\title{
Videomúsica, un nuevo producto cultural hipertextual
}

\author{
Evelyn CAMPOS \\ Andrea SANCHEZ
}

Tanto la imagen como la música son formas de expresión esencialmente humanas y su producción nos ha acompañado a lo largo del desarrollo evolutivo de la especie. Desde la época de las cavernas, el hombre ha utilizado la imagen como vehículo de representación e incluso como lenguaje. La música, por su parte, nació unida a las manifestaciones rituales y religiosas. Hoy, la cultura moderna o postmoderna -como plantean ciertos autoresproduce una interesante forma expresiva que combina ambos lenguajes: la videomúsica.

El éxito explosivo que significó la cadena televisiva MTV -que dedicaba su programación entera a la difusión de diferentes videoclips- va en directa relación con los nuevos valores y características de la sociedad contemporánea, postmoderna y occidental, que son la fragmentación, el narcisismo y lo pulsional.

Desde esta perspectiva, el videoclip es una manifestación artístico-cultural que ya no puede ser abordada como una mera fijación visual de determinada pieza musical, sino como un producto nuevo, que implica procesos de identificación y sentido particulares. El videoclip es un conjunto de representaciones simbólicas que se relacionan con el imaginario del artista. En este momento, planteamos a un sujeto en tanto cuerpo y una relación inexplorada en el ámbito de la videomúsica, un producto que es otra entidad diferente a la suma de sus partes. Abordar la música, las imágenes y el cuerpo por separado, ignorando los vínculos entre sí y la dinámica de sus relaciones, no da cuenta de lo audiovisual en tanto producto cultural.

Esta posibilidad abre un campo de investigación semiótica nuevo, que sigue la línea investigativa de Rafael Del Villar, en tanto utiliza la pulsionalidad como elemento nodal en la conformación de la identificación. A partir de esto, es importante preguntarse cuál es la naturaleza de la relación imagen-cuerpo-música y qué implicancias tiene en lo contemporáneo, en razón del protagonismo cada vez mayor que ocupa lo audiovisual en nuestra cultura.

\section{Antecedentes teóricos}

Desde el campo de la semiótica se desarrollan, en líneas de investigación paralelas, una semiótica de la música, otra de la imagen y por último una relacionada con el cuerpo. La propuesta de Del Villar es, precisamente, combinar estas vertientes de saberes especializados, generando una semiótica audiovisual que además involucra al cuerpo en su dimensión pulsional, es decir, como manifestación del imaginario e identificable empíricamente a través de flujos energéticos. Este artículo no reportará en profundidad las distintas teorías a las que convoca, pues cada una de ellas es merecedora de una discusión propia. En vez, propondremos una primera aproximación de manera de rescatar las ideas centrales que permitan un diálogo entre ellas. Es este diálogo el que finalmente posibilitará abordar el tema de la videomúsica con propiedad.

\footnotetext{
* Licenciadas en Comunicación Social del Instituto de la Comunicación e Imagen. Universidad de Chile.
} 
Desde la perspectiva de la semiótica de la música, existen dos líneas de investigación pertinentes. La primera es de Eero Tarasti, que propone que la música tiene una estructura narrativa, es decir, sigue una forma de relato lineal, con un comienzo, desarrollo y desenlace. Esta estructura es a la vez acrónica o atemporal, en el sentido de que, al igual que un enunciado, responde a una organización lógica, independiente del tiempo y el espacio. Es por tanto una estructura invariante. Así como una novela puede ser leída en distintas épocas y lugares, la partitura musical no es modificada por el tiempo o la geografía. En su artículo "Hacia una gramática narrativa de la música", explica que "en primer lugar, el enunciado musical puede contener un significado semántico, y en segundo lugar, el enunciado musical puede ser presentado de una manera que le otorgue un significado semántico. Dicho de otra manera, la narratividad se encuentra tanto en el nivel del enunciado musical como en el nivel de la enunciación musical" ${ }^{\prime \prime}$. Ni el tiempo ni el espacio intervienen la música, la única variable que podría intervenir la significación de ese texto musical es la interpretación o enunciación, en palabras de Tarasti. Y agrega que "el intérprete de la música es quien transfiere por su interpretación el enunciado puramente 'descriptivo' en el nivel modal, otorgándole su propia dinámica de deseo subjetivo"”2. De esta forma, la música se transforma siempre, con la ocasión de su ejecución, en una comunicación persuasiva.

David Lidov, por su parte, suma a esta visión lógica de la música una intervención corporal, a partir del momento en que define a la música como una acción en y del cuerpo. Esto hace que la relación entre música y cuerpo sea intrínseca y determinante. El autor identifica la corporeidad en el gesto que hace el cuerpo cuando produce lo musical, cuando advierte que "los gestos sintetizan unidades molares expresivas de actividad motora, en partes del cuerpo tales como, la laringe, el torso, etcétera, son unidades totales no fácilmente divisibles"3. Un ejemplo de esta situación es el gesto facial cuando se imposta la voz. En definitiva, asimila los gestos musicales a los musculares como equivalentes, estableciendo que se conectan por un comportamiento interior, un estado de ánimo. Si bien el gesto es fisiológico e inarticulado, para transformarse en música debe trascender el cuerpo y organizarse en una estructura que Lidov llama la "mente". El cuerpo, entonces, se sitúa en dos polos: lo exosomático, que es el terreno de lo objetual y lo lógico; y lo endosomático, que es el terreno de lo subjetivo e inarticulado.

En este punto de la discusión teórica, es importante introducir a Del Villar, por cuanto define la música como una experiencia somática totalizadora, ya no sólo circunscrita al gesto muscular, sino definida como una experiencia en la que interviene el imaginario, los archivos de mundo posibles de los implicados en el proceso. Desde este punto de vista, la música contendría una carga psíquica pulsional o inconsciente; además de ser una vibración que puede manifestarse en un significante, esto es, transmite una información de contenido, a la vez que una información pulsional, medible a partir de las características del sonido como fenómeno físico, esto es, una onda energética que se puede graficar en los ejes de frecuencia y amplitud.

\footnotetext{
${ }^{1}$ TARASTI, Eero. Vers une grammmaire narrative de la musique. Pág. 4 En Revista Degrés, Nº52. Bruxelles. 1987. Traducido por las autoras de este artículo.

${ }^{2}$ TARASTI, Eero. Op. Cit. Pág. 10.

${ }^{3}$ LIDOV, David. Mind and body in music. Pág. 77. En Revista Semiótica, Volumen 66 - 1/3. Ed. Mouton de Gruyter. Berlín, Ámsterdam, New York. 1987.
} 
Parece natural evocar, en este momento, las reflexiones de Gerard Chazal, quien define al cuerpo como una doble interfase en su dimensión fisiológica y somatopsicológica. El concepto de doble interfase sitúa al cuerpo como una frontera, un límite, pero también como una superficie de intercambio, es decir, un espacio donde transcurren flujos de información en ambos sentidos y en los dos planos que mencionamos (entre los órganos y el entorno del organismo; y entre el Yo y el Otro). El autor desarrolla la idea de cuerpo como doble interfase anotando que "nuestro cuerpo pertenece al mundo con el que hay que entrar en comunicación, y esta comunicación de nosotros al mundo se hace en nosotros mismos, en nuestro cuerpo propio que sentimos en su esfuerzo físico" ${ }^{\text {. Luego, esa }}$ información se entremezcla confundiéndose los opuestos de tal manera que se produce una tercera sustancia. No hay ni pura materialidad, ni conciencia pura, sino más bien una mixtura que no es estática.

Esta particular condición permite que el hombre se informe por su medio físico y social, y, recíprocamente, lo forme, modifique y reconstruya permanentemente. Al respecto, Chazal dice que "nos convertimos en pura comunicación material, nos reabsorbemos en este proceso de comunicación y apropiación para configurarnos, de esta manera, como "transmisores de formas y de sentidos", el mundo y que recíprocamente, el mundo esté en nosotros. Edgar Morin habla de una "proyección-identificación" en la que "el sujeto, en lugar de proyectarse en el mundo, absorbe el mundo en sí mismo" ". Adoptando estas perspectivas, el arte como producto cultural no solo revela caminos perceptivos, sino que carga con significaciones que establecemos en un espacio y tiempo determinados, tanto por parte del sujeto-creador como del sujeto-percibiente: la interfase comunica lo inmaterial, materialmente.

Así como Lidov postulaba la unión entre lo musical y lo muscular a través del gesto, Chazal afirma que el cuerpo nunca deja de reenviarnos a la imagen de nuestros placeres más secretos. Tenemos, por lo tanto, un cuerpo y una representación remitiendo ambas a la imagen, al concepto psicoanalítico de imaginario.

En esta dirección, el cine sería aquella máquina capaz de producir imaginarios, esa interfase que hace aflorar lo subyacente según lo entiende Chazal para con la práctica pictórica. En "Estética del cine" Jacques Aumont y otros autores describen los flujos de intercambio producidos entre el espectador y el film para remitir así a un imaginario dando lugar al arte como mediador entre el sujeto y la sociedad.

Se reafirma nuevamente el rol de interfase del cuerpo, pues lo mental, lo psíquico se reabsorbe en la apariencia del cuerpo. En este sentido, las técnicas del cine también son provocaciones, aceleraciones e intensificaciones de la "proyección-identificación" - de la que habla Morin- que superan el marco del personaje, haciendo que el espectador se sumerja tanto en el medio como en la acción del film.

Para el psicoanálisis freudiano, el concepto de identificación ocupa un lugar central en tanto es el mecanismo básico para la constitución imaginaria del Yo, que también debe pasar por una identificación secundaria ingresando luego a la esfera de lo simbólico. En el cine también se da una doble identificación como la que plantea Freud. Es el espectador cinematográfico quien se identificara en dos etapas con el film al que se expone.

\footnotetext{
${ }^{4}$ CHAZAL, Gérard. Interfaces. Pág. 47. Editorial Champ Vallon. Francia. 2002.

${ }^{5}$ CHAZAL, Gérard. Op. Cit. Pág. 44.

${ }^{6}$ AUMONT, Jacques; BERGALA, Alain; MARIE, Michel y VERNET, Marc. Estética del cine, Espacio fílmico, montaje, narración, lenguaje. Pág. 243. Editorial Paidós Comunicación. España. 1985.
} 
Christian Metz establece así una "identificación primaria cinematográfica" que corresponde a la identificación del sujeto de la visión con su propia mirada, remitiendo a la experiencia totalizadora de la recepción de imágenes, donde el cuerpo del sujeto espectador está inmóvil en el cine y es sólo mirada, es por ello que el espectador se identificara directamente con la cámara. Para Metz, "el espectador se halla ausente de la pantalla como percibido, pero también se halla presente y hasta omnipresente como percibiente" vez, la "identificación cinematográfica secundaria" apunta a la identificación del espectador con el relato fílmico o con los personajes y actores narrativos que en él se desarrollan. Este nivel identificatorio representa el conflicto entre el deseo y la ley que experimenta todo individuo, el cine propone al espectador una representación de su lucha interna.

Así, el cuerpo interfase permite que el espectador sea proyector y pantalla a la vez, el sujeto a la vez que emite, recibe; a la vez que proyecta, registra. Y en esta experiencia con lo cinematográfico, vive un proceso que se desarrolla en el plano energético. La energía inconsciente, como la que se expresa en los archivos de imágenes, también se expresa en la inserción del texto en el cuerpo. Esto implica una carga y descarga energética propia, de acuerdo a los archivos visuales y a la realidad material percibida.

Deleuze y Guattari han definido el inconsciente como energía, lo que implica decir que todos los aparatos culturales son una extensión del propio cuerpo. Para Deleuze, el cuerpo "es aquello en lo cual el pensamiento se sumerge o debe sumergirse, para alcanzar lo impensado, es decir, la vida" $"$. Sin embargo, los conceptos de tiempo y movimiento y su relación entre sí en la imagen en secuencia son abordados solo desde el plano del relato, olvidando la dimensión energética.

\section{Música-cuerpo-imagen en la videomúsica de Björk}

Como hemos visto en la discusión precedente, el fenómeno de la videomúsica puede abordarse de manera parcelada, puesto que ninguna de estas teorías basta por sí sola para abarcar la relación hipertextual que el sujeto establece al momento de la creación, percepción e inteligibilización del producto cultural, compuesto de distintos soportes. Por otra parte, ninguna de ellas rescata la importancia de la dimensión musical en tanto organizadora de la puesta en imágenes. Por esto, es imprescindible aprehender la videomúsica a partir de todos los elementos que la componen, de manera combinada: la música, el cuerpo y la imagen.

Identificando esta necesidad, la investigación titulada "Análisis semiótico del inconsciente de Björk" aborda el tema de la videomúsica, a partir de un estudio que da cuenta de dicha hipertextualidad abarcando cada uno de los textos que estructuran el producto musical en la escena artística contemporánea.

La investigación consistió en analizar en profundidad dichos fragmentos, siguiendo la teoría fractal de Mandelbrot, quien propone que en la naturaleza se puede encontrar la estructura del todo no en la repetición de elementos sino en las partes constitutivas, en los fragmentos. De esta manera, la estructura del árbol está contenida en la estructura de las nervaduras de una de sus hojas, pues "el número de escalas de longitud de las distintas

\footnotetext{
${ }^{7}$ METZ, Christian. Psicoanálisis y cine: el significante imaginario. Pág. 54. Editorial Gustavo Gili. España. 1977.

${ }^{8}$ DELEUZE, Gilles. La Imagen-tiempo, estudios sobre cine 2. Pág. 251. Editorial Paidós. Argentina. 2005.

9 BARRIENTOS, Elisa, CAMPOS, Evelyn, MORA, Maira, RAMÍREZ, Pamela y SÁNCHEZ, Andrea. Análisis semiótico del inconsciente de Björk. Tesis de Licenciatura. ICEI. Universidad de Chile. 2005.
} 


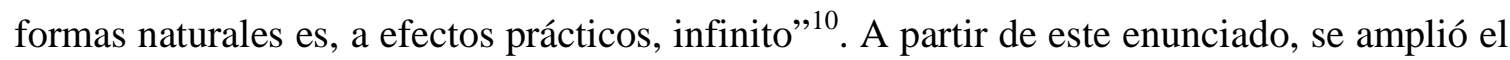
análisis hasta construir su estructura a partir de funcionamientos mínimos, develando los mecanismos relacionales entre un fragmento y otro, se tomaron en cuenta cuatro subconjuntos en sus interrelaciones: el video clip Jóga, la letra de la canción y su estructura energética (todos ellos generados en un mismo período histórico, 1997), y posteriormente sus dibujos, publicados en "Um Úrnat frá Björk" (Acerca de Úrnat por Björk), un libro de poemas anterior (1984) con no más de 100 copias.

Centrar una investigación semiótica en la creación artística de la cantante islandesa Björk, al investigar el videoclip como producto cultural, se justifica básicamente por el interés de la artista en desarrollar la dimensión visual de la música. Para Björk la imagen es crucial dentro de su carrera musical, pues sería un elemento que propicia la comprensión de su emocionalidad. En la entrevista publicada en la revista Index Magazine, aparecida en julio del año 2001, afirma: "La razón por la que trabajo con la imagen es para ayudar a la gente a entender mi música, entonces, es muy importante ser la misma emocionalmente tanto en la imagen como en la música. La mayoría de las personas tiene más desarrollados los ojos que los oídos. Si ellos ven una cierta emoción en la fotografía, entonces ellos entenderán la música"12.

De esta manera, Björk manifiesta -a priori- una reflexión en torno a los tres elementos centrales que propone este artículo como línea de investigación, a saber, la música, el cuerpo y la imagen. ¿Cómo opera la relación entre estos tres elementos, es decir, cómo se produce la implicación energético-pulsional del cuerpo en la secuencialidad de la música y la imagen? Esta pregunta implica dilucidar el inconsciente de autor, a partir de la reconstrucción semiótica de las manifestaciones artísticas.

En este punto, cabe destacar que para el análisis de los fractales audiovisuales se utilizaron herramientas metodológicas de la semiótica audiovisual y pictórica, con base en la teoría de códigos y análisis pulsional propuestos por Rafael Del Villar ${ }^{13}$. Para el análisis de la letra de "Jóga", apelamos a las teorías semióticas del texto escrito de Claude LéviStrauss, Julia Kristeva y Jean Petitot Cocorda. Los resultados obtenidos se coligieron con información contextual (biográfica) de la cantante a modo de validación.

La canción Jóga, perteneciente al disco Homogénic (1997), es un intento de himno a Islandia. El videoclip se enmarca en un período histórico de tensión, donde la cantante reconoce un quiebre con respecto a la forma de trabajar en sus anteriores producciones, pues con Homogénic (1997), ella tomó completamente el control de las decisiones dejando de lado las estrechas colaboraciones con otros músicos, internándose en un trabajo mucho más personal. Además, Björk se involucró directamente en la creación de este videoclip dirigido por Michel Gondry, llegando a considerarlo como uno de sus favoritos, en la medida en que está basado en la naturaleza y el modo en que ella experimenta la particular geografía islandesa. El clip de Jóga es un recorrido por los diversos paisajes naturales

\footnotetext{
${ }^{10}$ MANDELBROT, Benôit. La geometría fractal de la naturaleza. Pág. 15. Tusquets. Barcelona. 1997.

${ }^{11}$ BJÖRK. Um Úrnat Frá Björk. Edición Bad Taste. Islandia. 1984.

12 TELLER, Juerguen. Björk, 2001. En Index magazine 2001: http://www.indexmagazine.com/interviews/bjork.shtml (Consultado el 02/11/2005).

${ }^{13}$ DEL VILLAR, Rafael. La materialidad a través del cual se transmite la información en el texto audiovisual o la problemática de los códigos. Proyecto de Investigación Fondecyt N ${ }^{\circ} 1000954$, año 2000, Departamento de Investigaciones Mediáticas y de la Comunicación, Universidad de Chile, titulado "Dibujos Animados en Chile: sintaxis, circulación y recepción". En Escuela de Periodismo, Universidad de Chile: http://www.periodismo.uchile.cl/documentos/delvillar-codigos.pdf (Consultado el 25/05/2005)
} 
islandeses, pasando por los volcanes, la nieve, ríos y otros para llegar al corazón de Björk, en el cuál está contenida esa misma tierra.

Los resultados que arrojó el análisis del videoclip revelan que la organización de la imagen está subordinada o es llevada en todo momento por la música como en una percepción más oriental del espacio-tiempo -es decir, circular y no lineal-, pues la estructuración de la música no es simétrica, sino que parte de una cercanía al equilibrio energético de la naturaleza para continuar con una condensación progresiva.

Para efectos del análisis musical, la estructura rítmica se entendió como un todo reconstruido a partir de sus segmentos constituyentes, arbitrariamente fraccionados. Corresponden a estructuraciones rítmicas en acto, que se relacionan unas con otras, bajo términos específicos y que llamamos "formantes", según la denominación dada por Nicolás Ruwet (1967-1972). Son, en definitiva, instrumentos que tienen un comportamiento similar desde el punto de vista de la onda energética del sonido que generan, por eso establecen, entre sí, relaciones de equivalencia (cuando sus ondas energéticas se comportan de manera similar, desde el punto de vista perceptivo) y de contrapunto (cuando hay antítesis rítmica, producida por el contraste entre los principios constitutivos perceptivos de cada formante). En esta investigación, determinamos como formantes principales a la voz, violines, bajos y sintetizadores, cada uno de ellos organizados bajo lógicas distintas, desempeñan un rol particular que va cambiando de acuerdo a la progresión del videoclip. Lo importante es develar su comportamiento en relación a los demás. Así, descubrimos dentro de la estructura musical, la voz tiene absoluto protagonismo, reafirmando la importancia del sujeto.

En relación al inconsciente, recogemos la descripción teórica preliminar de Sigmund Freud, donde se establece que la pulsión funciona como una condensación/desplazamiento. Pero más que nada, recurrimos a Wilhelm Reich, quien, usando un electroscopio, detectó variaciones energéticas de la materia viviente. Con ello estableció la equivalencia, empíricamente medible, que tiene la materia viva con las situaciones de condensación/desplazamiento planteadas por Freud. De esta manera, se establece que la pulsión son los flujos o fluctuaciones de energía que tratan de restablecer el equilibrio energético que está ligado al placer. Hay equilibrio, entonces, cuando la descarga energética iguala a la tensión. Y desde este punto de vista, se puede abordar la pulsión identificando las fluctuaciones entre condensaciones y desplazamientos en la onda energética de la videomúsica.

En el caso de "Jóga", el analizador de espectro de sonido nos permitió detectar una tensión progresiva, dada la relación de contrapunto entre los formantes de los bajos y la voz en donde los primeros aplastan la presencia de la última. Luego, esa tensión llega a una catástrofe, dada por una tensión multidimensional y el ingreso trial del formante de sintetizadores, lo que implica tensiones continuas, permanentes, que advierten una tensión de otro tipo. Y luego un clímax (puntos máximos de condensación y desplazamiento) al irrumpir todos los formantes anteriores, aumentando la tensión que será resuelta hacia el final, donde el equilibrio está determinado básicamente por una predominancia del formante voz, una hegemonía que lo lleva incluso a escindirse en dos estructuras, para así alcanzar un estado de equilibrio similar al de la primera lexis. Se recupera el equilibrio entre el yin y el yan iniciales.

En base a la pulsión, o dinámicas energéticas del sonido, advertimos que los códigos narrativos y cromáticos se organizan de acuerdo a esas fluctuaciones energéticas de la onda sonora. De esto se desprende que existen dos planos con respecto a la cosmovisión 
en Björk. El primero hace referencia a una concepción occidental de la vida en tanto está asociada a la naturaleza, al crecimiento, al movimiento y a lo verde. El segundo plano tiene relación con la idea de caleidoscopio sobre la cual se organiza el espacio-tiempo, no es lineal, sino que asociativo, una estructura holística sobre la cual se conjugan los distintos códigos identificados. Estos dos planos presentados conjuntamente, a modo de engranaje, son propios de la posmodernidad en razón de su sincretismo.

Del análisis estructuralista de la letra se desprende, nuevamente, una configuración de sentido particular de Björk y su cosmovisión. A pesar de que está de acuerdo con una configuración suprema del mundo, entiende que la inserción del hombre en éste se hace con respecto a su condición emocional y sensible, para sentirse parte constituyente de la tierra misma. Björk encuentra su equilibrio en la inestabilidad natural y climática de Islandia, precisamente los datos contextuales confirman este deseo, pues la realización del álbum corresponde a un período en que la artista estuvo por mucho tiempo alejada de su país.

En cuanto a la información que reporta el último fractal, los dibujos de "Um Úrnat frá Björk", se puede desprender que en la artista hay un conflicto, una tensión energética en el interior, que es necesario expresar y delimitar.

Los dibujos representan, al igual que el video clip y la letra de la canción "Jóga", una manifestación de la particular cosmovisión de Björk, en la que tanto la naturaleza como los sujetos están compuestos de la misma energía y los mismos conflictos, que en esencia, comparten una misma pulsión y una misma realidad.

En el desarrollo de la propia identidad y del propio imaginario, de la propia pulsionalidad, observamos el mismo conflicto que aparece con la forma de una contención energética que se quiere exteriorizar, pero que es impedido por un condicionamiento externo. En el clip está representado por los formantes de los bajos (elemento regulador); en la letra se expresa en la imposibilidad de acceder a su objeto de deseo, que es su tierra, la inestabilidad de la naturaleza, para lograr el equilibrio; y en los dibujos, por los trazos y el croma.

El extenso análisis de cada fractal proporciona información valiosa relativa a la dimensión imaginaria del artista. En el caso de Björk existen dos ejes principales que se articulan como oposición. Por una parte, se encuentra un espacio enmarcado por una lógica mecánica de la sociedad, por aquello que remite a un orden establecido, a una socialización, o principios constitutivos del ser social. Y por otra, la energía que aparece vinculada a la tierra, el nexo con la naturaleza que determina otro motor de acción e identificación, centrado en la conducta inestable del medio ambiente. Se conjugan aquí, por lo tanto, dos dimensiones constitutivas del yo: por un lado, la cultural simbólica, que tiene que ver con las identificaciones secundarias propuestas por la teoría psicoanalítica, donde el sujeto ha diferenciado su yo de lo externo, y ha escogido un modelo a seguir, una función social debiendo adquirir normas y pautas sociales. Tal que para Del Villar esto "implica la identificación con roles, con identificaciones que hacemos de nosotros mismos respecto a nuestra identidad en la vida." 14 . Por otro, se expresa en Björk lo individual imaginario.

Siguiendo a Lacan, el hombre al nacer perdería su estado de equilibrio inicial, la homeostasis, y esa pérdida será irrecuperable. No obstante lo moverá hacia una búsqueda

\footnotetext{
14 DEL VILLAR, Rafael. Información simbólica/información pulsional: los tipos de información que transmiten los significantes audiovisuales en condiciones de estabilidad y catástrofe. En Escuela de Periodismo, Universidad de Chile: http://www.periodismo.uchile.cl/documentos/delvillar-japoanimacion.doc (Consultado el 14/04/2005).
} 
permanente. Del Villar indica que "en el imaginario se constituirán los primeros objetos de la pulsión, aquellos sustitutos de la carencia de equilibrio energético: el sujeto se aliena en su 'representación', con ese objeto seré yo, sin embargo, dichos objetos nos son simbolizados, no habrá separación entre la cosa y el hombre, son sólo huella del equilibrio energético" ${ }^{\prime 15}$. El imaginario es la esfera de la pulsionalidad, aquello que no puede ser simbolizado, pero que tiene que ver de todas maneras con la restitución de la homeostasis, con los flujos de la energía.

Esta última esfera es la que aparece como subyacente y homogenizada en todas las manifestaciones artísticas de la artista finlandesa. Existe en Björk un lugar primordial para el imaginario, para la fluctuación energética y es a partir de ésta que ella se sitúa en lo social. La identificación del sujeto creador no pasa por asumir una norma social. Björk asume que en su creación musical se aleja del canto lírico, pese a que la voz es decisiva en su propuesta estética. Afirma que "de una manera general, la voz está conectada al alma. La técnica no debe intervenir como un artificio, sino que debe servir a optimizar todas estas

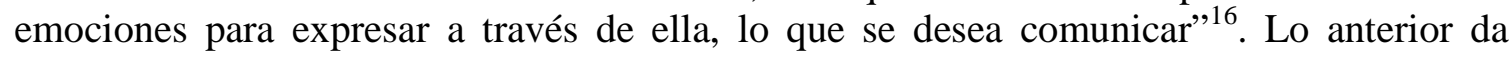
cuenta más bien de la proyección al mundo externo de su propia interioridad. En esta dirección, la naturaleza es entendida como un devenir irracional, emocional, pulsional, una exterioridad que se enraíza profundamente en el sí mismo.

Lo que tenemos, entonces, es la confirmación de que el cuerpo, en tanto energía, es una doble interfase. Tanto en el plano fisiológico (donde el sujeto creador se proyecta al exterior a través de la voz, en el caso de Björk.) como en el plano somatopsicológico (lo subjetivo, el imaginario del artista).

Toda exteriorización será por ende una manifestación corporal, en esta dirección, la creación artística, musical y visual, no es más que una manera de estructurar la pulsionalidad, la energía que conforma el imaginario del sujeto productor. El cuerpo es el gesto musical y muscular: la fluctuación vocal. El cuerpo es la imagen de un placer oculto: la añoranza de la inestabilidad del paisaje.

Actualmente, el texto ya no se considera como un bloque ordenado, lineal, sino como una reunión de fragmentos que se vinculan los unos con los otros, sin perjuicio de poseer lógicas de distinto orden. Así mismo, la videomúsica es un producto que se estructura tridimensionalmente, sus ejes son la música, el cuerpo y la imagen. La función que combina a las tres es la energía.

La hipertextualización -la conjunción de múltiples textos de naturalezas variadasha producido cambios en los procesos cognitivos que se expresan notablemente en nuestra cultura. El conocimiento no puede más ser totalmente considerado como un corpus fijo que se transmite, sino que debe obligatoriamente integrar la puesta en acto de un conjunto, considerar a los productos culturales un movimiento continuo, un pulso a rastrear.

\section{Referencias bibliográficas}

AUMONT, Jacques; BERGALA, Alain; MARIE, Michel y VERNET, Marc. Estética del cine, Espacio fílmico, montaje, narración, lenguaje. Editorial Paidós Comunicación. España. 1985.

\footnotetext{
${ }^{15}$ DEL VILLAR, Rafael. Op. Cit.

${ }^{16}$ RENAULT, Gilles. "Chanter équivaut à descendre une colline en glissant", entrevista a Björk. En: All Björk: http://www.allbjork.com/fr/spe/itw/index.php?itw=23 (Consultado el 29/10/2005)
} 
BARRIENTOS, Elisa; CAMPOS, Evelyn; MORA, Maira; RAMÍREZ, Pamela y SÁNCHEZ, Andrea. Análisis semiótico del inconsciente de Björk. Tesis de Licenciatura. ICEI. Chile. 2005.

BJÖRK. Um Úrnat Frá Björk. Edición Bad Taste. Islandia. 1984.

CHAZAL, Gérard. Interfaces. Editorial Champ Vallon. Francia. 2002.

DELEUZE, Gilles. La Imagen-tiempo, estudios sobre cine 2. Editorial Paidós. Argentina. 2005.

DEL VILLAR, Rafael. La materialidad a través del cual se transmite la información en el texto audiovisual o la problemática de los códigos. Proyecto de Investigación Fondecyt No 1000954, año 2000, Departamento de Ciencias Mediáticas y de la Comunicación, Universidad de Chile, titulado "Dibujos Animados en Chile: sintaxis, circulación y recepción". En Escuela de Periodismo, Universidad de Chile: http://www.periodismo.uchile.cl/documentos/delvillar-codigos.pdf (Consultado el 25/05/2005)

DEL VILLAR, Rafael. Información simbólica/información pulsional: los tipos de información que transmiten los significantes audiovisuales en condiciones de estabilidad y catástrofe. En Escuela de Periodismo, Universidad de Chile: http://www.periodismo.uchile.cl/documentos/delvillar-japoanimacion.doc $\quad$ (Consultado el 14/04/2005).

LIDOV, David. Mind and body in music. En: Revista Semiótica, Volumen 66 - 1/3. Editorial Mouton de Gruyter. Estados Unidos. 1987.

MANDELBROT, Benôit. La geometría fractal de la naturaleza. Tusquets. Barcelona. 1997. España. 1977.

METZ, Christian. Psicoanálisis y cine: el significante imaginario. Editorial Gustavo Gili.

RENAULT, Gilles. "Chanter équivaut à descendre une colline en glissant", entrevista a Björk. En: All Björk: http://www.allbjork.com/fr/spe/itw/index.php?itw=23 (Consultado el 29/10/2005)

TARASTI, Eero. Vers une grammmaire narrative de la musique. En: Revista Degrés, No52. Bruxelles. 1987. Citas traducidas por las autoras de este artículo.

TELLER, Juerguen. Björk, 2001. En: Index magazine 2001: http://www.indexmagazine.com/interviews/bjork.shtml (Consultado el 02/11/2005). 